\title{
Identidad e individualidad como motores en la construcción de la inmunología*
}

Identity and Individuality as Driving Forces behind the Construction of Immunology

Alfonso Arroyo Santos ${ }^{\dagger}$

\begin{abstract}
Resumen
La distinción entre propio y ajeno ha sido uno de los pilares de la inmunología contemporánea y fuente de grandes controversias en el campo. Al presente, se presume que lo propio es una metáfora introducida en la génesis de la inmunología contemporánea como una manera de dar cuenta de la inmunogenicidad. Sin embargo, en este trabajo desarrollamos la idea que hablar de lo propio fue la manera en que Frank Macfarlane Burnet logró la síntesis disciplinar que dio origen a la inmunología, al permitirle negociar aquellos aspectos que contribuirían las disciplinas que fundaron al campo, entre otras, la bioquímica, la medicina, o la biología molecular. Detrás de estas disciplinas hubo y ha habido grandes visiones de lo que debe ser considerado biológico, y es en la toma de postura frente a dichos debates en que lo propio toma sentido.
\end{abstract}

Palabras clave: inmunología - propio - organismo - teleología - mecanicismo

\begin{abstract}
The distinction between self and non-self has been central to contemporary immunology and a source of great controversy. At present, it is presumed that the self is a metaphor introduced in the genesis of contemporary immunology as a way of accounting for immunogenicity. However, in this paper we develop the idea that talking about the self was the way Frank Macfarlane Burnet achieved the disciplinary synthesis that gave birth to immunology. As we argue, the notion of self allowed Burnet to negotiate the disciplinary, methodological and theoretical aspects immunology would inherit from its parent fields, among others, biochemistry, medicine, or molecular biology. These disciplines have quarreled historically with particular views of what should be considered biological. The self takes form by siding with particular parts of these debates.
\end{abstract}

Keywords: immunology - self - organism - teleology - mechanism

\footnotetext{
* Recibido: 10 de Junio de 2014. Aceptado con revisiones: 30 de Agosto de 2014.

+ Centro de Información Geoprospectiva, México. Para contactar al autor, por favor, escribir a: agripas@gmail.com. Metatheoria 5(1)(2014): 49-63. ISSN 1853-2322.

(C) Editorial de la Universidad Nacional de Tres de Febrero. Publicado en la República Argentina.
} 


\section{Introducción}

En el trabajo presente se discutirá que la discriminación entre propio y ajeno, eje rector de la teoría inmunológica contemporánea, fue introducida con el fin de negociar la síntesis disciplinar que dio origen a lo que hoy día conocemos como inmunología. Por "síntesis disciplinar" se quiere destacar el hecho de que ciertas disciplinas, por ejemplo, la inmunología, la filogeografía o la biología de sistemas por nombrar tres ejemplos, tienen su origen en la síntesis de diversos campos. Estos campos "originarios" incorporan a la nueva disciplina no tan sólo teorías, métodos o preguntas, sino también, los valores que formarán la visión de lo que en adelante habrá de considerarse objetivo, válido, justificado o en pocas palabras, aquello que habrá de calificarse como "ciencia buena". Observar que el conjunto de elementos que podrá ser considerado ciencia buena varía de campo en campo según se sigan distintas tradiciones, pero para fines de este artículo, nos centraremos en antinomias que vienen desde la génesis de la biología como disciplina y que podemos conceptualizar como las relaciones entre teleología y mecanismo, externalismo e internalismo, explicación y descripción, o abstracción y concreción. Es nuestra tesis, que cada uno de estos debates representó una toma de postura que queda reflejada en la noción del reconocimiento a lo propio.

Para probar nuestro punto, se marcará el nacimiento de la inmunología contemporánea en la segunda mitad del siglo XX con el ascenso de la llamada Teoría de la Selección Clonal (TSC) atribuida a Frank Macfarlane Burnet. Si bien dicha teoría es fruto del trabajo de varios autores, el mérito de Burnet fue haber logrado la síntesis que permitió dar un motor a la disciplina, al unificar distintos intereses sobre la respuesta inmune venidos de campos tan cercanos y lejanos como la bioquímica, la medicina, la bacteriología, o la naciente biología molecular. El análisis mostrará cómo cada una de estas disciplinas trajo consigo una visión particular de lo que debía normar la inmunología, que quedó unificada artificialmente con la introducción de la discriminación entre propio y ajeno como criterio de inmunogenicidad.

El argumento se desarrollará de la siguiente manera: primero discutiremos brevemente qué es eso de "disciplina sintética". Mencionaremos desarrollos parecidos, sobre todo los debidos a Lenoir, Galison y Cambrosio y Keating. Enseguida presentaremos un panorama general del origen de la inmunología moderna con el propósito de mostrar la influencia que tuvieron distintas disciplinas. Finalmente, discutiremos cómo se negoció la síntesis de la inmunología contemporánea alrededor de la noción del reconocimiento a lo propio.

Antes de comenzar un par de aclaraciones. Primero, que este trabajo descansa sobre la historia de la inmunología pero no debe leerse como un ensayo histórico sobre el origen de la inmunología contemporánea. Se trata de un artículo filosófico en el que se quiere comprender la manera en que se constituyó la inmunología contemporánea. A pesar de ello, no debe pensarse que se trata de pequeños episodios históricos fuera de contexto sino que la investigación original descansa sobre un trabajo histórico profundo que desafortunadamente, ha de ser presentado muy someramente en el formato de un artículo. Aquellos interesados en la historia de la inmunología recomendamos los trabajos de Arthur M. Silverstein (1999), Pauline M.H. Mazumdar (1995) o Alfred I. Tauber (1994).

Segundo, que a lo largo del trabajo se hablará de disciplinas y se explotará, por ejemplo, las diferencias entre la medicina y la bioquímica. Es claro que lo que presentamos es una caricatura pero esperamos encontrar en la exageración los argumentos que nos permitan reflexionar del porqué de las controversias en inmunología. Que el universo del conocimiento biológico sea dividido en disciplinas discretas es un problema que debe ser considerado en otra arena.

\section{Las disciplinas sintéticas}


En el contexto del artículo presente llamaremos "disciplina sintética" a aquella que surge del estudio de un conjunto de fenómenos, problemas, conceptos,... originalmente desarrollado en el marco de distintas disciplinas. Así descrito, uno podría decir que todas las disciplinas son disciplinas sintéticas ya que en algún momento, su objeto de estudio lo fue de otras disciplinas "originarias". Por ejemplo, la bioquímica es fruto de la síntesis entre la biología y la química, como la biología a su vez fue la síntesis de la medicina y la historia natural, que a su vez fue fruto de... Sin embargo, lo que nos interesa es discutir el entramado de relaciones académicas, institucionales, teóricas, metodológicas, económicas, políticas, personales,... que permiten la construcción de una identidad tal, que después formará una nueva disciplina (ver por ejemplo, Lenoir 1997). En este sentido, hablar de disciplinas sintéticas implica comprender el origen de las disciplinas al exponer tal entramado de relaciones. Es claro que una labor tan vasta no puede ser abordada en el contexto de un artículo, pero sí que hay maneras de exponer tal entramado vía el análisis de ciertos recursos clave de las disciplinas: por ejemplo, con el análisis de sus conceptos, de (algunas de) sus prácticas, o con su lenguaje (i.e. Lenoir 1997, Shapin \& Shaeffer 1985, Woolgar \& Latour 1986).

En este trabajo motivaremos la discusión del origen de una disciplina sintética, en este caso la inmunología, a través de la introducción del reconocimiento a lo propio, una metáfora a decir de Tauber (1994), que sentó las bases de lo que hoy conocemos como inmunología. La noción de disciplina sintética descansa en los aportes de 4 autores: Timothy Lenoir, Peter Galison y Alberto Cambrosio y Peter Keating. Lenoir entiende las disciplinas científicas como "sitios para construir y mantener formas de identidad social y cultural" (Lenoir 1997, p. 3). Lo importante para el caso que nos ocupa, es que Lenoir piensa que, al ser objetos culturales, las disciplinas son más que nada, sitios de acción donde las habilidades políticas, económicas, instrumentales de sus miembros, son las que toman la batuta.

Por otra parte, Galison (1997) se basa en la antropología lingüística para entender cómo dos áreas de conocimiento generan dinámicas de comunicación entre ellos dado que, como es de esperarse, sus lenguajes difieren de maneras, uno diría que irresolubles. La solución según Galison, es la creación de "zonas de intercambio", lenguajes criollos que permiten que las dos culturas desarrollen un lenguaje común. Es claro que lo que se pone en juego en las zonas de intercambio no es tan sólo el significado de ciertos términos, sino también, la coordinación entre acción y creencia, lo que lleva en última instancia, a la creación de nuevas disciplinas.

Cambrosio y Keating (2003) transitan por caminos similares. Su preocupación tiene que ver con los vínculos entre la ciencia biológica básica (llamada hoy día "biomedicina") y la clínica, y cómo de su interacción surgen nuevas maneras de entender la diferencia entre lo normal y lo patológico. De nueva cuenta, se trata de dos campos, pareciera que muy diferentes, que en esta ocasión son vinculados vía las "plataformas". Según Cambrosio y Keating, las plataformas no son "cosas" sino más bien, maneras de organizar entidades, tanto naturales como artificiales, y artefactos de distintas clases: políticos (políticas de salud), materiales (los aparatos que se usan cotidianamente en la ciencia básica y que después pasan a ser instrumentos fundamentales en la clínica) y simbólicos (por ejemplo, los marcadores fruto de la investigación básica que después pasan a ser sinónimo de salud o enfermedad, y se convierten en motivación para seguir cierto estilo de vida).

En este trabajo se parte de preocupaciones similares, y por ello, tomamos como base el marco de estos autores para entender un problema muy concreto: cómo es posible que "el reconocimiento a lo propio", un algo que ni es una entidad, ni es un proceso, ni es un mecanismo biológico, sino que es un dictum, se haya convertido en la piedra angular de la inmunología contemporánea. Entenderemos el origen de las disciplinas en el sentido de Lenoir con lo que la conformación de la inmunología fue fruto de la creación de una nueva cultura en que se darían ciertas prácticas, creencias, intereses políticos, económicos,... a partir de la toma de postura de ciertos individuos frente a los grandes debates de la biología en torno a la teleología, el mecanicismo, o la abstracción. De Galison se tomará 
la idea de que el reconocimiento a lo propio fue el lenguaje (con todas sus implicaciones) que tendió los puentes entre las distintas disciplinas que dieron origen a la inmunología, en tanto que de Cambrosio y Keating tomaremos la noción de plataforma para mostrar cómo las preocupaciones entre el desarrollo teórico y su aplicación clínica configuraron el campo.

\section{La inmunología}

Por inmunidad se entiende generalmente, las condiciones que permiten a un organismo no enfermar; en este sentido, inmunidad significa estar exento de enfermedad y por tanto, el sistema inmune sería aquello responsable de la defensa del organismo. Que el foco de la inmunología sea la enfermedad tiene todo el sentido: se supone una rama de la medicina y tradicionalmente se entiende que la medicina está dirigida al enfermo. Sin embargo, también es posible definir inmunidad como aquello que permite mantenernos sanos, lo que, en términos contemporáneos, podría definirse como la situación de equilibrio entre el organismo y su ambiente. Por ambiente no debe entenderse únicamente el medio externo, el lugar donde vive el individuo, sino también su ambiente interno, por ejemplo, aquel formado por la multitud de bacterias que viven en nuestro organismo y sin las cuales sería imposible mantenerse sano (o en equilibrio).

Sea como fuere, es raro encontrar un texto en inmunología que dé la definición positiva de la inmunidad. Por mencionar tres libros de texto muy populares: dice el Ruby "El sistema inmune es un sistema de defensa sobresaliente que ha evolucionado para proteger a los animales de microorganismos patógenos y el cáncer" (Goldsby et al. 2001, p. 1, traducción propia). O que tal el Abbas: "Una definición más incluyente de la respuesta inmune, es (que se trata) de la reacción, tanto a componentes microbianos como a macromoléculas, como proteínas o polisacáridos, y partículas químicas pequeñas que se reconocen como ajenas, sin importar la consecuencia fisiológica o patológica de tal reacción" (Abbas et al. 2014, p. 1). Y finalmente, el Paul: "La inmunología es la ciencia médica por excelencia" (Paul 2008, p. xiii).

Citamos algunos de los textos más populares en la enseñanza de la inmunología para mostrar cómo el imaginario inmunológico habla de la defensa del individuo contra según qué entidades. Y esto es así, porque como ya dijo William E. Paul en la última cita, la idea es que la inmunología es la ciencia médica por excelencia, y la medicina siempre ha estado asociada a curar, proteger, prevenir la enfermedad. Sin embargo, queda por ahí un elemento extraño que saca a relucir Abul K. Abbas: la idea de lo ajeno. Que la defensa siempre es contra algo ajeno a nosotros es una trivialidad: nos defendemos de bacterias, virus, hongos, células enloquecidas que (pareciera) dejan de reconocerse como tejido propio. Sin embargo, ¿qué es lo propio? ¿Los elementos codificados por nuestro genoma? Si esto es así, entonces queda el grandísimo problema de por qué no atacamos a la microbiota. Pareciera que si la inmunidad se definiera de manera positiva, se estaría en mejor piso para hablar de lo ajeno. Todas esas bacterias que conforman la microbiota del ojo, del intestino, de la piel, de... y que nos ayuda a estar sanos, ¿en qué sentido son ajenas? El vocabulario de lo propio y ajeno fue introducido en el momento fundacional de la inmunología como ciencia biomédica, y es nuestra tesis que tiene su origen no en las exigencias de la medicina, sino que fue la manera en que un grupo de individuos representados por Burnet, negoció la síntesis disciplinar que dio origen al campo. A continuación repasaremos la génesis de la inmunología contemporánea. La intención no es dar una historia exhaustiva, sino destacar las aportaciones de las distintas áreas.

\section{Breve historia de la inmunología contemporánea}

El despegue de la inmunología contemporánea se dio alrededor de la Segunda Guerra Mundial, por una parte, por el avance en el desarrollo de técnicas para el trasplante de tejidos, y por otra, por el 
interés que despertó en la comunidad bioquímica entender el origen de los anticuerpos. Para entrar en contexto, revisemos primero el trabajo de tres pioneros de la inmunología: Louis Pasteur, Robert Koch y Paul Ehrlich.

Pasteur y Koch fueron los primeros en demostrar que ciertas enfermedades eran debidas a microorganismos. Sus avances fueron sustentados sobre la base de dos supuestos muy importantes: 1) Que los microorganismos son causantes de las enfermedades infecciosas. Y 2) Que la inoculación en el individuo de microorganismos "atenuados" previene y combate dichas enfermedades. Tanto Pasteur como Koch se esforzaron mucho en probar el primer punto pero fracasaron para darle explicación al segundo. Sin embargo, el éxito práctico de las vacunas contra la rabia, el ántrax, el cólera, y un largo etcétera, fueron suficientes para dejar establecida la validez de ambos supuestos, incluso sin explicación satisfactoria.

Fue Ehrlich quien propondría una explicación para el supuesto 2 por medio de su Teoría de la Cadena Lateral. Para explicar el éxito empírico de las vacunas, Ehrlich postuló que cada célula del cuerpo presenta una serie de receptores, llamados cadenas laterales, que, en condiciones normales, cumplían funciones de nutrición celular. Sin embargo, por mero azar, los receptores también podían reconocer según qué componentes de los microorganismos. Cuando esto pasaba, el receptor perdía su función nutricional y pasaba a cumplir funciones de defensa del organismo al desencadenar cierta reacción que hacía que la célula engullera al receptor unido al microorganismo. Para dar cuenta de la especificidad de las vacunas, Ehrlich postuló que cada cadena lateral era específica para cada tipo de microorganismo: el número de cadenas laterales necesario para dar cuenta de tal fenómeno no pareció importante dado que se pensaba que había pocos microorganismos (Ehrlich 1900).

Con el paso del tiempo, la cadena lateral pasó a convertirse en el anticuerpo, o la entidad de defensa contra cuerpos extraños. El anticuerpo de Ehrlich tuvo muchos problemas desde el principio pero su puntilla fue, por una parte, el avance en la comprensión de las alergias lo que aumentó de manera dramática el número de anticuerpos necesarios para mantener la relación uno a uno con los anticuerpos (Löwy 2003), y por si fuera poco, el experimento de Karl Landsteiner (1945) quien consiguió obtener anticuerpos contra el dinitrofenol, una sustancia artificial. Estos avances insinuaban a ojos de los investigadores de la época, que el organismo tenía la capacidad innata de producir anticuerpos contra cualquier cosa. Fue tal insinuación la que atrajo la atención de las comunidades de bioquímicos quienes se interesaron en descubrir cómo era posible tal proeza. A partir de la década de 1930, se desarrolló una serie de teorías conocidas como de instrucción, por el supuesto de que la especificidad inmunológica debía ser instrumentada al nivel de la síntesis del anticuerpo. Las teorías más populares supusieron que, de alguna manera, el antígeno (la sustancia blanco del anticuerpo), debía instruir la síntesis del anticuerpo una vez que el individuo era expuesto a él, lo que explicaría cómo era posible encontrar anticuerpos contra lo que fuese tras inmunizar a los animales (Silverstein 1989).

\subsection{La Teoría de la Selección Clonal}

Para la década de 1950, el interés fundamental de la naciente inmunología era dar cuenta de esa capacidad aparentemente infinita de producir anticuerpos. Dado que se trataba de un problema vinculado a la síntesis de proteínas, los avances se dieron principalmente en el campo de la bioquímica. Comentar brevemente que, si bien ni la medicina ni la bacteriología volverían al primer plano de interés inmunológico sino hasta los avances de Burnet, hubo desarrollos muy importantes sobre todo durante la Segunda Guerra Mundial. Queremos destacar en particular, las investigaciones detrás del trasplante de tejidos y las aportaciones de Meter B. Medawar y Ray Owen. Antes de la Segunda Guerra Mundial, el éxito de un trasplante era terriblemente bajo, pero las necesidades de la guerra digamos que volvió imperativo encontrar soluciones. Gracias, en particular, al trabajo realizado por el grupo de Medawar, se concluyó que el rechazo de tejidos era resultado de una respuesta sistémica del organismo, 
o en otras palabras, resultado de una respuesta inmune (Billingham \& Medawar 1951). Asimismo, en 1945 Ray Owen demostró que aquellos animales que comparten el sistema circulatorio durante la etapa embrionaria (gemelos dicigóticos), son quimeras, esto es, sus eritrocitos son una mezcla entre células propias y células de su gemelo. Seis años más tarde, el grupo de Medawar demostraría que dichos animales no rechazan tejidos trasplantados entre ellos.

Tal era el panorama en 1955 cuando Niels Jerne presentó su Teoría de la Formación de Anticuerpos por Selección Natural. La preocupación de Jerne era explicar la presencia de los llamados anticuerpos naturales en el suero no inmunizado: desde los avances de Ehrlich se sabía que era posible encontrar anticuerpos contra ciertas sustancias incluso antes de que el animal fuese expuesto a ellas. A este tipo de anticuerpos se les llamó naturales por la presunción que, de alguna manera, eran parte normal del individuo. Mientras estudiaba la dinámica del complejo antígeno- anticuerpo, Jerne comprobó que era capaz de obtener repetidamente anticuerpos contra un mismo antígeno en los supuestos sueros control, esto es, sin inmunizar y por ende, teóricamente incapaces de producir anticuerpos. Este re-descubrimiento llevó a Jerne a considerar que el individuo sintetizaba el universo de anticuerpos necesarios para cualquier antígeno antes de ser expuesto a él. Si bien Ehrlich tuvo el problema de explicar cómo era posible que el organismo produjera una cantidad aparentemente infinita de anticuerpos dado el requerimiento de que fuesen específicos para cada antígeno, Jerne no consideraba que esta relación tuviese que ser uno a uno, sino que un mismo anticuerpo podría interactuar contra varios antígenos a distintos grados de afinidad. Con esto, se abría la posibilidad de que el universo de anticuerpos fuese importante pero dentro de la capacidad de síntesis de proteínas del organismo (Jerne 1955).

La teoría de Jerne fue descartada casi de inmediato porque en 1956, Francis Crick enunció lo que se conocería como "el Dogma Central de la Biología", según el cual, la información genética seguía la ruta ADN-ARN-proteína y no podía pasar de proteína a ARN. Con ello, era imposible que el complejo antígeno-anticuerpo dictase la síntesis de los anticuerpos como presumían Jerne y todas las teorías de instrucción. Sin embargo, fue a partir de Jerne que Burnet encontraría la inspiración para enunciar la Teoría de la Selección Clonal. Dice Burnet:

\begin{abstract}
Nuestra idea es que cualquier forma satisfactoria de la teoría de Jerne debe involucrar la existencia de múltiples clones de células productoras de globulinas, cada una responsable de [producir] un sólo tipo de anticuerpo determinado genéticamente. Esto plantea inmediatamente la pregunta de cómo puede el complejo antígeno - anticuerpo localizar a la célula determinada genéticamente para producir el anticuerpo correspondiente. Claramente, la situación se simplificaría enormemente si el antígeno estuviese en la posición de reaccionar con el anticuerpo natural, o con un patrón equivalente a este, en la superficie de la célula que lo produjese (Burnet 1959, p. 54, traducción propia).
\end{abstract}

En 1959 Burnet presenta su teoría con una advertencia: "Para muchos investigadores, esta aproximación parecerá atrasada en comparación con la moda actual de llevar los conceptos bioquímicos hasta el límite en la interpretación de los fenómenos biológicos” (Burnet 1959, p. ix, traducción propia).

Podemos decir que los postulados centrales de la TSC son:

1. El organismo tiene la capacidad de producir el universo de anticuerpos necesarios para reconocer cualquier antígeno potencial. Esta información está codificada en el ADN del individuo.

2. Durante el proceso embrionario, las células productoras de anticuerpo inmaduras, necesitan de una señal negativa (no reconocer determinantes propios) para continuar su desarrollo.

3. El anticuerpo es presentado como un receptor en la superficie de las células linfáticas.

4. Durante la edad adulta, la unión con el antígeno provoca la proliferación y diferenciación de aquellas células con que se haya entrecruzado, a diferentes grados de 
afinidad.

5. Las células estimuladas producirán clonas de células específicas para su antígeno determinado, algunas de las cuales se diferenciarán para convertirse en células de memoria.

Observar que en esta reconstrucción, el postulado 1 responde a las exigencias de la joven pero ya importante biología molecular. Estamos a finales de la década de 1950 pero ya no es posible hablar de la producción de cualquier cosa a nivel del organismo sin que éste tenga que ver con lo genético. El postulado 2 pretende dar cuenta de aquello de lo "propio". Es a nivel del proceso embrionario en que se construye el inventario de aquellos elementos que serán considerados como propios al organismo (recordar los experimentos de Owen sobre gemelos dicigóticos). El postulado 3 toma en cuenta los avances de Jerne, en tanto que el postulado 4 pretende dar cuenta de la especificidad entre antígeno y anticuerpo. Por último, el postulado 5 fue inspirado por la bacteriología en que era cosa de todos los días aquello de trabajar con clonas.

Un resumen general sería que, durante la vida embrionaria, un proceso de interacción mutua entre los componentes del organismo provoca que, durante la vida postnatal, no se produzcan anticuerpos capaces de reaccionar con los componentes [propios] a su alcance. Las reacciones inmunes que incluyen producción de anticuerpo se originan (a) si entran al cuerpo antígenos que presenten determinantes extraños, (b) si por cualquier razón, componentes del organismo inaccesibles normalmente, se volviesen "accesibles", o (c) si las células productoras de anticuerpo se desvían de las restricciones impuestas durante la vida embrionaria. (...). La antigenicidad, por supuesto, siempre será relativa al hospedero - el animal utilizado para la producción de anticuerpos- y la superficie de cualquier antígeno proteico contendrá cientos de determinantes antigénicos potenciales inertes, dado que serán iguales a determinantes presentes en los componentes del hospedero. La calidad antigénica de la molécula, dependerá de la presencia de un pequeño número de determinantes antigénicos $\mathrm{A}, \mathrm{B}$, etc. que será diferente a cualquiera que esté presente en el hospedero (Burnet 1959, p. 34).

Es importantísimo decir que la TSC no era tan sólo un intento por explicar el funcionamiento del sistema inmune, sino también, una respuesta a la pretensión de reducir la explicación biológica al campo de la bioquímica tan en boga durante la primera mitad del siglo XX. Dice Burnet: "Mi visión particular sobre la situación de las células inmunes está basada francamente, en el deseo de obtener la representación más simple de la base celular de la producción de anticuerpo" (Burnet 1959, p. 46), "lo que puede ser descrito como un proceso estrictamente darwiniano a nivel celular" (Burnet 1959, p. 63).

\subsection{La época contemporánea}

Era 1959, la TSC sería reformulada por los siguientes 30 años desde numerosos frentes pero creemos correcto decir que todos ellos motivados por dos grandes cuestiones: por una parte, dar cuenta de esa capacidad extraordinaria del organismo para sintetizar un universo aparentemente infinito de anticuerpos, y por otra, explicar en qué consiste aquello de "propio". Por razones de espacio no es posible ofrecer un recuento de las transformaciones que sufrió la teoría original pero en los siguientes párrafos mencionaremos algunos de los grandes hitos de la inmunología que pudieron, aunque no de manera del todo satisfactoria, resolver las dos grandes preguntas del campo.

Como todos sabemos, la segunda parte del siglo XX se convertiría en el reino de la biología molecular y con ello, cualquier investigación en biomedicina tuvo en mayor o menor medida, que plegarse a los dictados del área. Por ello, la TSC debió hacer a un lado los mecanismos celulares y centrarse cada vez más en los aspectos genéticos para explicar convenientemente cómo se producía la diversidad inmunológica (tan sólo insinuada en el presupuesto 1). Paradójicamente, Burnet volvía a tropezar en los mismos problemas que Ehrlich un siglo antes: una vez más, la evidencia experimental apuntaba a una mayor diversidad inmunológica que la presumida por la teoría por lo que, otra vez, 
primaría la explicación de la diversidad de los anticuerpos sobre los mecanismos celulares del sistema inmune.

Burnet mismo comenzaría la actualización de su teoría a partir de 1962. La versión original de la TSC asumía que todos los anticuerpos posibles estaban presentes en el organismo adulto codificados en una región del genoma (muy) susceptible a sufrir mutaciones. Esto está explícito en el postulado 1, que en aquella época asumía que todos estos anticuerpos representan una variedad más bien limitada: 5000 según Talmage (colaborador de Burnet; ver Talmage 1959), un millón según Jerne. Ahora, y con la presión de números crecientes de anticuerpos, Burnet especula que las células linfáticas podrían sufrir mutaciones somáticas espontáneas durante su proliferación tras el estímulo antigénico. De resultar por azar un anticuerpo con mayor afinidad, éste sería el seleccionado. Con ello mantiene los números dentro de un rango razonable para sus posturas teóricas, pero da un cambio sustancial al contenido teórico del primer postulado ya que no todos los anticuerpos posibles estarían predeterminados. Aun así, dado que la preocupación principal es justificar el número de anticuerpos posible, digamos que Burnet "salva" el sentido de la teoría.

Mientras Burnet luchaba contra los grandes números, otros investigadores responden al reto de explicar qué es eso de "propio". Los primeros en saltar a la palestra fueron Melvin Cohn y Peter Bretscher (Bretscher \& Cohn 1970, Bretscher 1999). Con el mecanismo propuesto por Burnet sobre mutaciones al azar, resultaba que la célula podría generar anticuerpos potencialmente reactivos contra determinantes propios. Recordar que los anticuerpos contra elementos propios del organismo eran eliminados durante la vida embrionaria por lo que nada se podría hacer si estos de alguna manera, aparecían más tarde. A fin de contrarrestar el problema, Cohn y Bretscher introdujeron una segunda señal de selección durante la vida adulta. Así pues, ahora el destino de la célula productora de anticuerpos dependía de la interacción asociativa del antígeno y de la presentación de éste por una segunda célula que pasó a llamarse célula $T$ de ayuda. De acuerdo a esto, la interacción con el antígeno en ausencia de la célula $\mathrm{T}$ de ayuda provocaría tolerancia.

La célula $T$ de ayuda resolvía un problema, mantener bajo control mutaciones potencialmente peligrosas, pero a cambio, introducía un nuevo problema: ¿y quién regulaba a la célula de ayuda? Por ello, la teoría sería revisada drásticamente en 1975 con la incorporación de una señal de activación para las células de ayuda. En 1974, Rolf Zinkernagel y Peter Doherty descubrieron que el reconocimiento del antígeno por parte de la célula $\mathrm{T}^{1}$ sólo se puede hacer cuando éste se encuentra acoplado a un receptor llamado MHC. Zinkernagel y Doherty estudiaban la relación entre las células T y la infección por un virus en ratones, cuando observaron que si bien las células $T$ eran reactivas contra el virus, eran incapaces de atacar células infectadas de animales de distinta cepa (al animal del que provenían las células T). La explicación era que la célula necesitaba del estímulo no sólo del antígeno, sino además, de la proteína MHC propia. Con esto, la respuesta inmune sufría un cambio sustancial: su accionar dependía tanto del reconocimiento de lo ajeno (el antígeno) como de lo propio, el MHC. Aun así, los autores presentaron su descubrimiento dentro de la TSC:

Las células T son sensibles al "propio alterado", ya sea a antígenos H-2 modificados, o a estructuras codificadas por el complejo genético H-2 que normalmente no están presentes en la célula, o bien a una mezcla de antígenos virales con $\mathrm{H}-2$. [...] El concepto de lo propio alterado está en concordancia con la teoría de vigilancia inmunológica de Burnet, ampliada un tanto para incluir como una parte esencial, la respuesta a agentes infecciosos (Zinkernagel \& Doherty 1975, p. 1427).

Y como en una pesadilla contada por Jorge Luis Borges, el espejo se miraba a sí mismo y resultaba que la célula de ayuda controlaba a la célula $\mathrm{T}$, la cual a su vez era controlada por el antígeno y el MHC, pero ¿y quién controlaba a éstos? En 1975 Kevyn Lafferty y Alastair Cunningham propusieron una

\footnotetext{
1 Para entonces, los linfocitos habían sido divididos en dos grandes grupos según el lugar donde se desarrollaban: en el timo (célula T) o en la médula ósea (célula B por bone marrow). Las primeras contaban con el subconjunto de células de ayuda (célula $\mathrm{T}_{\mathrm{h}}$ ), y las segundas serían las productoras de anticuerpo.
} 
tercera señal y añadieron una célula más al juego estimulador: en esta ocasión, la célula $\mathrm{T}$ de ayuda, sería activada a su vez, por una célula coestimuladora, llamada APC, necesaria tanto para su supervivencia como para su función de ayuda. Obsérvese que la adición de esta nueva señal no resuelve el problema principal ¿quién ayuda a quién? Responder que son las APC, simplemente pasa la pregunta a una nueva entidad lo que permite preguntarse quién ayuda a las APC. Para intentar resolver el problema, se postuló que las APC son constitutivas, esto es, siempre están activadas.

Comentar por último, que la explicación a la diversidad extraordinaria de los anticuerpos se convertiría en uno de los grandes éxitos de la biología molecular en el siglo XX. El mecanismo, elucidado por el equipo del científico japonés Susumo Tonegawa, dice que el anticuerpo tiene una zona variable y otra constante. La zona variable es el sitio de unión con el antígeno y está subdividida a su vez en zonas hipervariables y de estructura. Existen 3 grupos de genes que codifican para la zona variable conocidos como V, D y J. En el ser humano existen alrededor de 200 genes tipo V, 20 D y 4 J, que se recombinan al azar para sintetizar la proteína. El juego combinatorio, más los nuevos anticuerpos producidos vía mutación y otros mecanismos extra genéticos, más el reconocimiento de que la relación antígeno-anticuerpo no es unívoca sino que cada anticuerpo reconoce un antígeno a distintos grados de afinidad, daban para dar cuenta de ese universo de anticuerpos, grande pero no infinito (Tonegawa 1983).

\section{La inmunología como la ciencia de lo propio}

De la exposición histórica presentada en las secciones a y b, es fácil ver que Burnet y seguidores toman elementos venidos de distintas áreas para construir la TSC. Por nombrar 3 ejemplos: 1) la bacteriología. El término "clon" puede resultarnos sumamente familiar al presente, sobretodo bajo la idea aquella de hacer copias exactas de individuos. Sin embargo, en la década de 1950, el término refería no a una técnica de copiado, sino a un conjunto de células, generalmente bacterias, que al reproducirse asexualmente hacía que todos los miembros fuesen genéticamente iguales. Si bien genéticamente iguales, eso no implicaba que fuesen copias idénticas ya que según las condiciones medioambientales, las clonas podían diferenciarse de distintas maneras. Sobre esta idea, Burnet postula que existirían células productoras de anticuerpos que, al ser estimuladas por el antígeno, se reproducirían para formar clonas. Sin embargo, diferentes condiciones permitirían la producción de células que produjesen anticuerpos con distintos grados de afinidad por el antígeno lo que permitía ofrecer un mecanismo que diese cuenta del número de anticuerpos sin proponer que el cuerpo produjese un número altísimo de células productoras de anticuerpo. 2) La biología molecular. Aunque en la década de 1950 la biología molecular estaba en pañales, ya era impensable proponer un proceso de producción masiva de células productoras de anticuerpo sin aportar un mecanismo genético detrás. Fue Joshua Lederberg (1959) quien postuló originalmente el cómo de este fenómeno según la idea de que la especificidad del antígeno es producto de una única secuencia de aminoácidos presente en el anticuerpo. La célula productora de anticuerpos, tiene a su vez, una secuencia única de nucleótidos que la codifican en el ADN, y dicha zona de ADN se encuentra en una región de alta mutabilidad que permite la reconfiguración al azar de los distintos sitios de unión del anticuerpo (esto, para dar cuenta del número de anticuerpos). Notar que esta idea es completamente especulativa pero para su época, está en línea con lo que se pensaba sobre mecanismos genéticos. 3) La medicina. Si bien la gran pregunta de la protoinmunología tenía que ver con cuestiones bioquímicas, los avances médicos en torno al trasplante de tejidos introdujeron quizá la idea más importante para la inmunología contemporánea, la noción del "reconocimiento a lo propio". Recordemos que durante la Segunda Guerra Mundial, la investigación en torno al trasplante de tejidos se volvió de suma importancia. La observación clave aquí fue que si bien no había mayor problema cuando se trasplantaba tejido de una parte del cuerpo a otra del mismo individuo, la cosa resultaba imposible cuando se quería trasplantar 
tejido de otra persona. En pocas palabras, el sistema inmune rechazaba lo que no reconocía como "propio". Burnet tuvo esta idea muy presente cuando postuló la TSC y supeditó todos los mecanismos biológicos a la idea de que debían discriminar entre lo propio y lo ajeno.

Mucho se ha dicho en torno a la noción de propio y ajeno (para un resumen ver Tauber 2014), pero en este artículo queremos proponer una nueva interpretación: Burnet introdujo estos términos para negociar la síntesis disciplinar que terminó por construir lo que hoy conocemos como inmunología. Observemos que, en el fondo, la teoría no necesita hablar de propio contra ajeno. Basta con dar cuenta de mecanismos celulares y genéticos para explicar los fenómenos asociados a la respuesta inmune. Por ejemplo, tiene todo el sentido decir que la teoría de Burnet tiene 2 grandes presupuestos: 1) El sistema inmune es capaz de producir el universo de anticuerpos necesario para identificar cualquier antígeno potencial; y 2) Cada célula inmune produce anticuerpos específicos para un antígeno determinado.

La noción de propio es secundaria y responde a la necesidad evidente de aclarar como un sistema tan diverso como el planteado es capaz de protegerse de sí mismo. Con ello, propio y ajeno, como dice Tauber (1994) deben tomarse más bien, como la metáfora que utilizó Burnet para enfatizar este punto. Sólo que la evidencia contradice esta aseveración: Propio ha pasado a convertirse en un término común del lenguaje inmunológico. Como dice Anne Marie Moulin (2000, p. 385): "La inmunología, que surgió a partir de la teoría de la enfermedad por gérmenes, ha evolucionado para proveer una visión global del organismo que subordina todos los procesos fisiológicos a un propósito común: la defensa y la representación de la identidad". Burnet mismo puso especial énfasis en la distinción propio y ajeno a lo largo de su exposición original sobre la TSC y trabajos posteriores, ${ }^{2}$ de una manera tal, que en ningún momento hace pensar que hable metafóricamente. Por ello, la TSC es más que nada, una teoría que propone que el sistema inmune discrimina entre elementos propios y ajenos.

\subsection{La Síntesis}

De acuerdo a la tesis que se defiende en este artículo, el reconocimiento a lo propio supone la manera en que Burnet negoció la síntesis disciplinar que daría nacimiento a la inmunología contemporánea. Recordar, como se mencionó en la sección 1, que por síntesis disciplinar se quiere destacar el hecho de que muchas disciplinas modernas nacieron de la fusión en intereses teóricos, metodológicos, experimentales, institucionales, políticos, económicos,... de un conjunto de disciplinas originarias. Como se dijo, esto es algo que pasa todos los días pero lo que queremos discutir particularmente, es el por qué ciertos elementos de cada disciplina originaria pasan a formar parte del corpus teórico, normativo, metodológico,... de la nueva disciplina sintética.

Es nuestra tesis, que el debate detrás de lo propio tiene que ver con antinomias que vienen desde la génesis de la biología como disciplina y que podemos conceptualizar como las relaciones entre teleología y mecanismo, externalismo e internalismo, explicación y descripción, o abstracción y concreción. La manera en que la TSC toma partido en cada uno de estos debates queda reflejado en los elementos que toma de uno u otro campo de las disciplinas que le dieron origen. Tomar elementos de aquí y de allá pudo hacer de la inmunología una mera colección de métodos y técnicas experimentales, pero para evitarlo, nada mejor que introducir el elemento que diera sentido a cada elección tal como se discutirá a continuación. Comentar antes que nada, que sin duda hay mucho que decir de la relación de la inmunología con los grandes debates de la biología, pero por razones de espacio la exposición será breve y más que nada, dirigida a mostrar cómo la inmunología, la TSC, toma una postura clara.

\subsubsection{Teleología y mecanismo}

\footnotetext{
${ }^{2}$ Ver, por ejemplo, Burnet $(1959,1972)$.
} 
Propio tal como lo introdujo Burnet, es un concepto completamente teleológico. Dice que el propósito del sistema inmune es salvaguardar la integridad, incluso la identidad del individuo. Sin embargo, hasta el presente, la mayoría de las discusiones en torno a lo propio se han centrado en la metáfora. Por ejemplo, dice Tauber, quizá el principal filósofo sobre la inmunología, que: "Lo 'propio inmunológico' -una formulación metafísica del sistema como un todo, elusivo y mal definido, es una metáfora ponderosa que pretende capturar la actividad total del Sistema Inmune” (Tauber 2014, traducción propia).

Ni una palabra sobre teleología sino en el carácter metafórico de lo propio. Sin embargo, es difícil entender cuál es la metáfora en la descripción del sistema inmune. No se parece por ejemplo, a la discusión de "nichos" ecológicos, de "paisajes" adaptativos, de "radiaciones" adaptativas, o de otras metáforas famosas en que uno ve de manera clara el uso que se le da a paisaje, nicho o radiación. En el caso de "reconocer lo propio" se va al grano: tal es el eje rector de la inmunología. ¿Dónde queda lo metafórico?

Sea como fuere, Burnet va al grano porque, recordemos, uno de sus intereses principales era separarse de la bioquímica y sus preocupaciones mecanicistas. Se abre así un primer campo en contra de una disciplina fundadora del campo. Cierta comprensión de lo biológico (en términos de biología celular y medicina) englobado en la teleología contra otra noción que defiende al mecanicismo. No que Burnet despreciara lo mecánico, a fin de cuentas, propuso y demostró muchos mecanismos a nivel celular. El punto era marcar la línea entre lo que veía como una reducción de lo biológico hacia la química, como se podía ver en el interés por hablar de mecanismos a nivel atómico, de interacciones entre cargas y otros elementos que eran el vocabulario con el que se explicaba la relación antígenoanticuerpo. En este sentido, la "ciencia buena" no tan sólo da cuenta de mecanismos y reacciones, sino que va más allá, ofrece explicar el por qué de tales mecanismos y procesos.

\subsubsection{Internalismo contra externalismo}

Otra discusión de largo alcance. En este caso, Burnet se alía del lado del internalismo para decir que el organismo cuenta de manera innata con todos los elementos necesarios para interactuar con su medio. Esta posición se lleva al extremo en la discusión sobre propio y ajeno, a pesar de como se dijo al principio, es problemático explicar qué hacer con la microbiota, algo bien sabido desde hace mucho tiempo. Proponemos que el problema tiene que ver con la manera en que Burnet conceptualiza la importancia del antígeno: en las teorías de instrucción, así como en la teoría de Jerne, el antígeno dirige de cierta manera la producción de anticuerpos. Aunque a finales de los 1940 Burnet también era partidario de dicha idea (ver Burnet \& Fenner 1949), cambia de parecer motivado en parte, por los avances que se han dado en la comprensión del trasplante de tejidos, pero sobretodo, por su postura abiertamente en favor de lo biológico, de lo que él entiende por "biológico". Burnet entiende que lo biológico tiene que ver con una lectura evolutiva vinculada a la síntesis moderna, la gran teoría en biología en la época de desarrollo de la TSC y décadas posteriores. Quizá por ello, la postura internalista sería la que tomaría mayor ímpetu en inmunología durante las décadas siguientes, llegando al clímax con la teoría idiotipo-antiidiotipo de Jerne en la que el sistema inmune es un espejo que sólo se mira a sí mismo y dónde solo hay reacción cuando por la razón que sea, se rompe la armonía entre sus partes (Jerne 1985). Con esta postura, la inmunología se alía con la biología molecular, en particular con su cerrazón en torno al gen omnipotente, con cierta visión de la bioquímica de la que de cualquier manera es aliada, y de la bacteriología porque de cualquier manera, si uno puede llevar clonas de células a diferenciarse de ciertas maneras es porque de antemano tienen tal capacidad (el medioambiente es secundario). Al elegir el internalismo, Burnet se alía con una visión de la biología que no sería puesta en entredicho sino hasta fechas recientes, con el ascenso de los sistemas y la epigenética, y que tuvo como consecuencia práctica, esa fobia enfermiza en contra de lo "ajeno", de los gérmenes que hacen que nos vendan jabones "que eliminan al 99\% de las bacterias". 


\subsubsection{Explicación y descripción}

Desde sus inicios, la inmunología ha vivido grandes controversias en torno a qué cuenta como una explicación adecuada. Pasteur por ejemplo, nunca ofreció explicación adecuada para el éxito práctico de sus vacunas, pero los casos de niños al borde de la muerte que de pronto recuperan la salud, hizo olvidar que nadie podía realmente explicar el por qué. Lo mismo pasó con Koch, y en cierta medida también pasó con Ehrlich dado que el desarrollo técnico de la época no permitió nunca estudiar las cadenas laterales: su éxito y su fracaso siempre estuvo basado en evidencia indirecta. Para Burnet, los mecanismos bioquímicos no eran explicativos. Si acaso describían ciertos procesos pero de ninguna manera explicaban el porqué de la inmunogenicidad. Si bien lo propio y lo ajeno pueden ser vistos como una manera fácil de hablar de tolerancia inmunológica, lo cierto es que se han convertido en el eje rector por medio del cual se han hecho los grandes avances teóricos y experimentales de la inmunología contemporánea. Y los que no han pasado por este filtro, han pasado por el de otros conceptos de estatus difícil, por ejemplo, vía la teoría del "peligro" de Polly Matzinger (2002). Aunque no es esta la arena para discutir qué cuenta como una explicación en biología, nos parece justo decir que en gran medida, la explicación biológica habla sobre mecanismos. $\mathrm{O}$ al menos así pareciera de consultar la literatura tanto científica como filosófica (ver, por ejemplo, Machamer et al. 2000, Glennan 2005 o McManus 2012). En este sentido, dar una explicación en biología es hablar de los mecanismos que dan cuenta de cierto fenómeno. Sin embargo, dijimos que Burnet explícitamente está en contra del mecanicismo por lo que no puede decir que la explicación inmunológica sea dar cuenta de mecanismos celulares, genéticos, bioquímicos. Algo más ha de haber, y ese algo tiene que ver con lo teleológico y por tanto, con el tipo de explicaciones que se han de tomar como correctas. Es nuestra opinión que nunca se ha puesto en duda que la explicación inmunológica sea mucho más que sólo dar cuenta de mecanismos. Las teorías rivales de la TSC comparten en gran parte los mecanismos que hemos comentado en este artículo pero se separan en la introducción del por qué el sistema inmune es reactivo contra según qué cosas. Matzinger (2002) dice que es porque se identifican "señales de peligro", Jerne (1985) dice que es porque se rompe el equilibrio entre las entidades que forman todo el organismo, Pradeau y Carosella (2006) dicen que es "discontinuidad en la presencia de cierto antígeno". Si algo ha convertido a la inmunología en una disciplina independiente de la biología molecular, la biología celular, e incluso de la medicina, ha sido la búsqueda de este porqué.

\subsubsection{Abstraccionismo contra concreción}

No hemos hablado de los grandes modelos matemáticos de la inmunología pero quizá sean el punto de quiebre más importante con respecto al menos, a dos de las disciplinas originarias, la bacteriología y la medicina. Con la toma de postura internalista, se vuelve completamente innecesario el estudio de casos clínicos o la recolección de parásitos para su análisis. Todo puede ser abordado por medio de un modelo porque, en última instancia, microorganismo o enfermedad son lo de menos, todo queda explicado a nivel del organismo. Y para ello, los modelos matemáticos juegan un papel fundamental. Indirectamente hemos mencionado dichos modelos en el relato histórico: a fin de cuentas, Talmage o Jerne calcularon el número de anticuerpos necesario al imaginar qué tan grande debía ser el universo de antígenos, la dinámica de los anticuerpos nunca abandonó el campo de la fisicoquímica, y muchas de las teorías rivales de la TSC lo que hacen es simular la dinámica de la respuesta inmune según qué grandes preceptos (peligro, discontinuidad, reconocimiento a lo propio y ajeno). Al final, Burnet no puede hacer a un lado a la bioquímica, una de las grandes progenitoras de la inmunología, pero sí puede dejar en un papel secundario a los mecanismos mientras entrona a la abstracción por medio de los modelos matemáticos.

A manera de resumen, hemos visto como el reconocimiento a lo propio otorga a la inmunología un carácter teleológico a la inmunología, la separa, como disciplina, de aquellas en que se prima al mecanismo como eje rector de la explicación, la vuelve completamente internalista ya que todo queda centrado en el organismo relegando al medio ambiente como algo que debe ser combatido, y prima los 
modelos de corte abstracto ya que, al ser lo propio un elemento ambiguo, solo puede ser operativizado por medio de modelos matemáticos que den cuenta de esos fenómenos en que lo propio es el rector de la respuesta inmune.

\section{Conclusión}

El propósito de este artículo ha sido explicar el origen de la discriminación entre propio y ajeno en inmunología, como motor de la síntesis que creó el campo. Por sintético queremos decir que las disciplinas se constituyeron por la aportación teórica, metodológica, normativa, de un conjunto de disciplinas "originarias". A grandes rasgos se mostró que la inmunología es un campo sintético en el que convergieron diversos intereses venidos de la bioquímica, la bacteriología, la medicina, la biología evolutiva o la biología molecular. Sin embargo, más que centrarnos en discutir los aportes puntuales en torno a métodos o teorías, la discusión giró en torno de las grandes antinomias de la biología: teleología y mecanicismo, externalismo e internalismo, explicación y descripción,... Aunque no fue dicho de manera explícita, cada disciplina originaria de la inmunología trajo consigo una postura con respecto a dichas antinomias. Así, el mérito de Burnet, en quien marcamos el nacimiento de la inmunología contemporánea, fue ante todo, negociar las posturas que tomaría la nueva disciplina lo que se sintetizó en la introducción de un elemento extrañísimo conocido como el reconocimiento a lo propio.

En la mayoría de los estudios históricos y filosóficos sobre inmunología, lo propio es conceptualizado ya sea como una metáfora, o bien como una manera de hablar mantenida por la tradición (Pradeau \& Carosella 2006). En este sentido, la metáfora es vista como una herencia de la medicina por construirse sobre grandes relatos que hablan de guerras y victorias, pero también como la manera en que se comprende al ser humano. Si bien el estatus de lo propio como metáfora es debatible, en este trabajo hemos mostrado como lo propio pasó a encarnar los valores sobre los que se fundó la inmunología según lo expresó el mismo Burnet: como una ciencia biológica (y por ello no acepta que el organismo sea reducido a un conjunto de mecanismos y se alía a cierta comprensión de la teleología), darwinista (aunque es más correcto decir que se vincula a la visión internalista de la síntesis moderna), empírica y sencilla (lo que da cuenta de las virtudes encontradas en la modelización matemática).

Mucho se ha discutido sobre el sentido de lo propio y las dificultades enormes que supone para comprender al sistema inmune desde un punto de vista meramente fisiológico. Sin embargo, las aportaciones filosóficas no han podido explicar satisfactoriamente el porqué de la situación, ya que, desde tal punto de vista, pareciera que lo propio fue únicamente un recurso teórico utilizado por Burnet para dar cuenta de la tolerancia inmunológica. Sin embargo, queda la gran pregunta de por qué los nuevos aportes teóricos hacen uso, otra vez, de (supuestas) metáforas para discutir sus propuestas. En el marco de este artículo, lo propio ha caído paulativamente en descrédito, no porque sea una metáfora que agotó su poder heurístico, sino porque se trata de un término que dio sentido a la disciplina bajo una óptica que ha quedado rebasada con el ímpetu de las nuevas ciencias biológicas vinculadas a lo "complejo" y a un creciente interés por integrar al ambiente a los recuentos biológicos. Atrás queda el internalismo de Burnet y más atrás queda la teleología superada al presente por el ideal mecanicista tras los estudios de sistemas complejos.

Bibliografía

Abbas, A.A., Lichtman, A.H.H. y S. Pillai (2014), Cellular and Molecular Immunology, Philadelphia: Elsevier. 
Billingham, R.E. y P.B. Medawar (1951), “The Technique of Free Skin Grafting in Mammals”, Journal of Experimental Biology 28(3): 385-402.

Bretscher, P. y M. Cohn (1970), “A Theory of Self-Nonself Discrimination”, Science 169:1042-1049.

Bretscher, P. (1999), "A Two-Step, Two-Signal Model for the Primary Activation of Precursor Helper T Cells", Proceedings of the National Academy of Science U.S.A 96: 185-190.

Burnet, F.M. y E. Fenner (1949), Production of Antibodies, Londres: Macmillan.

Burnet, F.M. (1959), The Clonal Selection of Acquired Immunity, Cambridge: Cambridge University Press.

Burnet, M.F. (1972), Auto-Immunity and Auto-Immune Disease, London: Medical and Technical Publishing Co.

Cambrosio A. y P. Keating (2003), Biomedical Platforms. Realigning the Normal and the Pathological in Late-Twentieth-Century Medicine, Cambridge, MA: MIT Press.

Ehrlich, P. (1900), “On Immunity with Special Reference to Cell Life”, Proceedings of the Royal Society (London) 66: $424-$ 448.

Glennan, S. (2005), "Modeling Mechanisms", Studies in History and Philosophy of Biological and Biomedical Sciences 36: 443-464.

Goldsby, R.A., Kindt, T.J. y B.A. Osborne (2001), Kuby Immunology, New York: W.H. Freeman \& Co.

Jerne, J.K. (1955), "The Natural Selection Theory of Antibody Formation”, Proceedings of the National Academy of Sciences USA 41: 849-857.

Jerne, J.K. (1985), “The Generative Grammar of the Immune System”, EMBO Journal 4(4): 847-852.

Lafferty, K.J. y A.J. Cunningham (1975), “A New Analysis of Allogeneic Interactions”, Australian Journal of Experimental Biology and Medical Sciences 53(1): 27-42.

Landsteiner, K. (1945), The Specificity of Serological Reactions, Cambridge, MA: Harvard University Press.

Lederberg, J. (1959), “Genes and Antibodies”, Science 129: 1649-1653.

Lenoir, T. (1997), Instituting Science. The Cultural Production of Scientific Disciplines, Palo Alto: Stanford University Press.

Löwy, I. (2003), “On Guinea Pigs, Dogs and Men: Anaphylaxis and the Study of Biological Individuality”, Studies in History and Philosophy of Biological and Biomedical Sciences 34(3): 399-423.

Machamer, P., Darden, L. y C.F. Craver (2000), “Thinking about Mechanisms”, Philosophy of Science 67: 1-25.

Matzinger, P. (2002), “The Danger Model: A Renewed Sense of Self”, Science 296: 301- 305.

Mazumdar, P.H. (1995), Species and Specificity. An Interpretation of the History of Immunology, Cambridge: Cambridge University Press.

McManus, F. (2012), "Development and Mechanistic Explanation”, Studies in History and Philosophy of Biological and Biomedical Sciences 43: 532-541.

Moulin, A.M. (2000), “The Defended Body”, en Cooter, R. y J. Pickstone (ed.), Companion to Medicine in the Twentieth Century, London: Routledge, pp. 385-398.

Owen, R.D. (1945), "Immunogenetic Consequences of Vascular Anastomoses Between Bovine Twins", Science 102: 400-401.

Paul, W.E. (ed) (2008), Fundamental Immunology, Filadelphia: Lippincott Williams \& Wilkins Publishers.

Pradeau, T. y E. Carosella (2006), “On the Definition of a Criterion of Immunogenicity”, Proceedings of the National 
Academy of Sciences USA 103: 17858-1786.

Shapin, S. y S. Schaffer (1985), Leviathan and the Air-Pump: Hobbes, Boyle, and the Experimental Life, Princeton: Princeton University Press.

Silverstein, A.M. (1989), History of Immunology, San Diego: Academic Press.

Talmage, D. (1959), “Immunological Specificity”, Science 129: 1643-1648.

Tauber, A.I. (1994), The Immune Self: Theory or Metaphor, London: Cambridge Studies in Philosophy and Biology.

Tauber, A. (2014), “The Biological Notion of Self and Non-self”, en Zalta, E.N. (ed.), The Stanford Encyclopedia of Philosophy, URL = http://plato.stanford.edu/archives/win2014/entries/biology-self/.

Tonegawa, S. (1983), "Somatic Generation of Antibody Diversity”, Nature 302: 575-581.

Woolgar, S. y B. Latour (1986), Laboratory Life: The Construction of Scientific Facts, Princeton: Princeton University Press.

Zinkernagel R.M. y P.C. Doherty (1975), "H-2 Compatibility Requirement for T- Cell- Mediated Lysis of Target Cells Infected with Lymphocytic Choriomeningitis Virus", The Journal of Experimental Medicine 141: 1427-1436. 